\title{
Cooperative Principle Maxims In Whatsapp Conversations Among Undergraduates In The Federal University Of Technology Akure, Ondo State, Nigeria
}

\author{
Otemuyiwa Abosede Adebola (PhD) \\ Department of English, College of Humanities and Social Sciences, \\ Joseph Ayo Babalola University, \\ Ikeji Arakeji, Osun State, Nigeria.
}

\begin{abstract}
During interlocution, sentences, clauses, phrases, words are used. The utterances made can then be classified in various ways for the purpose of analysis or research. They can be classified according to length by counting the number of words in each utterance, for instance. The utterances can be classified grammatically or structurally in the English language along a number of dimensions: their clausal type and complexity; activepassive; statement-question-request-exclamatory and so on. This study examines the rate of flouting/obeying of Grice's Cooperative Maxims in WhatsApp conversations among undergraduates in the Federal University of Technology Akure, Ondo State, Nigeria. Theoretical framework for the study Cooperative Principle by Grice 1975 was used to analyse the data. The data include selected conversations from October 2016 to February 2017. The results revealed that the level of cooperation is high to some extent between the conversationalists in FUTA's data. The maxims of relation and manner were of the same percentages (7.4) and these revealed that the rate of obscurity and the rate of diversion from the topic of discussion was high. This study therefore recommends that students should be more truthful and concise in making their thoughts known in other to reduce flouting of Maxims of cooperation in conversations.
\end{abstract}

Keywords: Cooperative Principle, WhatsApp, Undergraduates, Flouting/Obeying

\section{INTRODUCTION}

Utterances depend majorly on the interlocutors' status, the purpose and the context of discussion. For instance, in a student-teacher situation, when there is a third party, the level of discussion will be different from when the student and the teacher are alone. This study attempted to define 'language' which is a vital communicative tool in this research according to Osisanwo (2003) who defines language as: "human vocal noise or arbitrary graphic representation of this noise used systematically and conventionally by members of a speech community for purposes of communication". p. 1 Language as a vocal noise that is graphically represented and used systematically for communication is what we have in the case of 'WhatsApp' which is the source of data for this study.

Language performs various functions that some pieces of literature emphasized. For instance, Halliday (1970) discusses three major functions of language as textual, ideational and interpersonal functions. The three functions were tagged metafunctions. Some other scholars propose functions of language as expressive/emotive, directive/conative/persuasive, poetic, referential and contextual. Communication, on the other hand, according to Merriam Webster is the act or process of using words, sounds, signs or behaviours to express or change information or to express ideas, thoughts, feelings, etc., to someone else. It can also be referred to as a message that is given to someone: a letter, telephone calls, to mention but a few. It can 
also be the ways of sending information to people by using technology. Communication involves the process which includes encoding, message, channel, decoding, feedback, grape vine, body language, verbal information, filtering, selective perception, information overload, jargon and active listening.

This study examines the rate of flouting/obeying of Grice's Cooperative Maxims in WhatsApp conversations among undergraduates in the Federal University of Technology Akure, Ondo State, Nigeria.

The need to identify the frequency and examine the implications of obeying and/or flouting of the maxims of Grice's Cooperative Principle in the selected WhatsApp conversations among undergraduates of the Federal University of Technology, Akure calls for this study. Hence, this paper is out to answer the following questions; i) what is the frequency of flouting and/or obeying of the various maxims of Cooperative Principle and ii) to what extent has the frequency of obeying or flouting of the maxims affected message coding in the selected WhatsApp conversations among undergraduates from the Federal University of Technology, Akure, Ondo State, Nigeria.

\section{WHY THE FRAMEWORK}

The Cooperative Principle is very good for effective communication and it revealed people's behaviour in conversation. Successful communication is guided by cooperative principle and finally, it facilitated conversation.

\section{Studies on Grice's Cooperative Principle}

Li (2015) carried out a study on the application of cooperative principle in oral English learning. This study opines that the study of cooperative principle will improve English skills in students especially speaking skills and stimulate the students learning interest. Kazemi \& Ebrahimi (2016) investigated the functions of Gricean cooperative principle in two Iranian newspaper; "Hamshahri" and "Jame Jam". The study revealed that if the masses do not observe the maxims, they cannot be in the dark and that they will still understand what they read in the newspapers. Xiaosu (2009) examined conversational implicatures of humour in American situation comedy "friends" The study revealed that conversational implicatures work as an offrecord language strategy for keeping communication processing in an appropriate way. Juez (1995) is of the opinion that ironic means violating the quality maxim specifically and violating the other three too. Hadi (2013) examined various representations and interpretations of Grice's Cooperative Principle. The source of controversy in this study is that the 'cooperation' has different interpretations. Olsen (2015) researched into the ambiguous nature of sarcasm using Grice's Maxims. The study revealed that the exclusion of punctuation could have minimized interference but that may also have cause some tweets to appear less positive than intended .The study is also of the opinion that the omission of more robust results would eliminate contextual cues.

Kheirabadi \& Aghagolzadch (2012) examined news as a mutual conversational activity between the media and its audiences, and so the rules guiding conversational process must be obeyed in the news production process. The study advised journalists to consider these four cooperative principle maxims when preparing their news. Zor (2006) explored the relationship between coherence -related problems of Turkish EFL students and their English essays may have inadequacies in English writing skills. Abdi, Rizi \& Tarakoli (2009) examined how Gricean principles could be used too in writing research articles. The study reported that the analysis exposed the researcher and readers to a new classification of meta-discourse strategies of collapse and disclaimers. Shuwei (2004) explored the similarities and differences 
in the way Chinese TV host observes Grice's four maxims. The study revealed that foreign language learners of English in China can improve their communicative skills through observation of Grice's cooperative principles adequately during conversations in order to avoid misunderstandings. Zhou (2009) investigated Cooperative Principle in the teaching of Oral English. The study proved that cooperative principle can be applied to spoken English teaching. Banjo (2014) opined that Grice Cooperative principle is a highly productive theory. He declares that it is not only in conversations that these four maxims of manner, quality, quantity and relevance could be used but that they could be used for the analysis of written documents too. The study explains how the maxims function in journalistic writings. (pp. 8-9). Napis (2008) examined hedging and flouting of conversational maxims in the movie of John Tucker must Die. He suggested that readers should try to obey the rule of conversation and in movie; characters should obey their directors' command so that the story can run properly.

Lindblom (2001) examined cooperating with Grice: a cross-disciplinary metaperspective on users of Grice's Cooperative Principle. The survey demonstrates that scholars who study discourse as utterance are most interested in the Cooperative Principle Maxims and conversational implicature, while they critique the notion of a general cooperative principle; scholars who study discourse as social interaction are more critical of the maxims. The study concluded that no articulation of how the cooperative principle could consistently describe discourse as an utterance, social interaction, and social context exists, but such an articulation could answer critiques of the cooperative principle, open the concept for greater crossdisciplinary use and provide new vocabulary for describing discourse. Taghiyev (2017) explored violation of Grices' maxims and ambiguity in English Linguistic jokes. The study concluded that in linguistic jokes, the humorous effect is achieved through lexical-semantic or structural-syntactic ambiguity where Grice's maxims are violated. Pham (2010) investigated how native speakers of Vietnamese observed Grice's maxims. Three hundred conversational contributions in live talk exchanges from varied Vietnamese television channels and naturally occurring discourse were analysed. The results show that understanding different ways of speaking in different cultures is a crucial point in intercultural communication and (foreign) language teaching and learning. Attardo (1990) examined the violation of Grice's maxims in jokes. The study claims that the study of jokes and other kinds of humorous texts can yield interesting insights on the nature of cooperative linguistic communication and more specifically, on the relative status of the maxims.

\section{Studies on WhatsApp}

Conner (2015) investigated how to use WhatsApp to conduct research. He was of the opinion that everybody uses WhatsApp, and that emoticons can be used to capture intonation facial expressions and body language. He further said that they reduce ambiguity and allow users to add emotional context to what is being said. He highlighted that assignments, projects can be given to people in a group by their facilitators. Yeboah \& Ewur (2014), worked on the impact of WhatsApp messenger usage on students' performance. The study revealed that WhatsApp takes much of the study time of the students and that distractions characterize the students' behavior in school. Not only that, that WhatsApp destroys the spellings and grammatical construction of sentences by the students. However, the study believes that WhatsApp allows effective flow of information and sharing of ideas among students. Cross (2017) examined the uneasy relationship between African governments and social media. The study declares that social media sometimes offer potential platform for the dissemination of hate speech and incitement to violence. The study also mentioned that news and information are rapidly spread among large number of people. Violations of electoral process by governments or other human rights violations are exposed online. The study also reported that surveillance and censorship opportunities are enjoyed by governments just mention but a few. Higgs (2014) considered the 
effect that texting might experience due to the introduction of internet-based Apps for communication. The study compares texting with other messaging applications.

\section{METHODOLOGY}

The data for this study are the WhatsApp conversations on iPhones of undergraduates in the Federal University of Technology Akure, Ondo State, Nigeria.

Theoretical framework for the study Cooperative Principle by Grice 1975 was used to analyse the data. The data include selected conversations from October 2016 to February 2017. The purpose for the choice of location for the subjects/participants for this study, which are undergraduates is that, most of them have the type of phones (iPhones) on which WhatsApp can be used. Also they are informed on how to use the whatsApp application.

WhatsApp, the data for the study was chosen because, it is a contemporary application where people pour out their minds on various matters that bother them and sometimes get instant solutions to their problems from family and friends. Moreover, many lessons were learnt by individuals and groups through messages sent among them. In addition, it is safer, cheaper, easier to operate, and the response is faster than that of text messages.

Six conversations were randomly collected from six undergraduates on their phones' WhatsApp application for analysis. The data comprised 25 strings out of which 18 strings were analysed. Both individual and group chats were used for the study. There was no specific theme that controlled the data collection since the researcher was at the mercy of whoever was magnanimous enough to release his/her phone for the collection of data. In addition the subjects were free to discuss any issue or subject of their choice with their friends.

For the collection of the data, the subjects were approached at FUTA by the researcher, to discuss the purpose of the collection of the data which is "research". After the consent of the subjects had been sought and given, the selected conversations on the subjects' WhatsApp pages were screenshot and forwarded to the researcher's phone. Descriptive qualitative and quantitative approaches were used for the analysis of the collected WhatsApp conversations.

The data were analysed using first four strings in each datum. The frequency of obeying and flouting of the four maxims of cooperation used by the conversationalists were identified, and the implications of obeying and flouting of the maxims on the addressee and the e-context (which is determined by the smileys and emojis on the WhatsApp pages), in the selected WhatsApp chats/conversations were explored in frequency and percentages. Gender constituents were not recorded by the researcher but through the conversations, the researcher was able to deduce the sex of the interlocutors. Below is the model with which the analysis was carried out. 


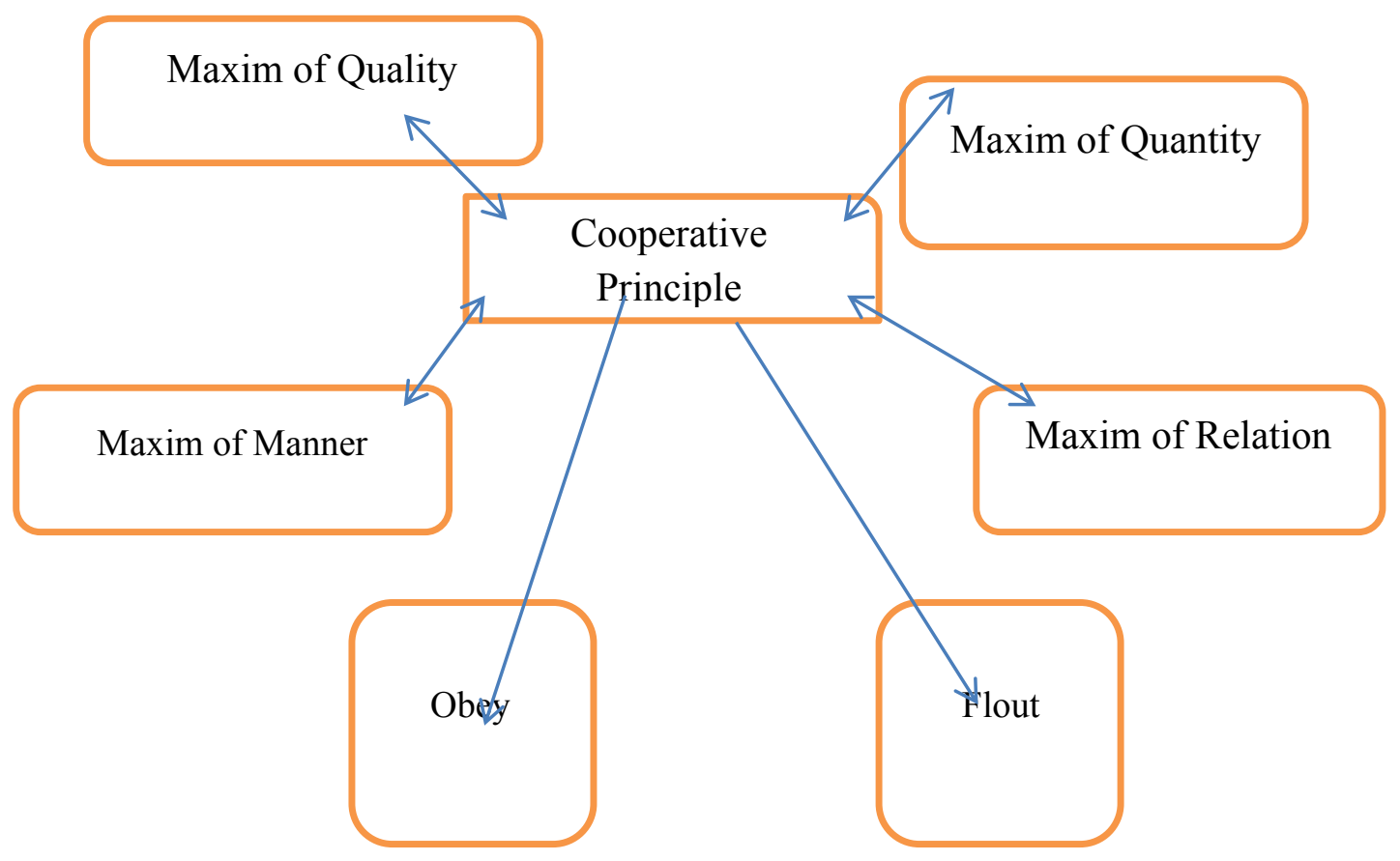

Source: Otemuyiwa Abosede Adebola

This is the cooperative principle's model for analysis of data of the selected FUTA's undergraduates' WhatsApp conversations. This model examined the frequency of obedience and violation/flouting of the cooperative maxims of Grice 1975 which made it known whether communication was successful between interlocutors. This model made the analysis clear and simple.

\section{ANALYSIS AND DISCUSSIONS OF THE FEDERAL UNIVERSITY OF TECHNOLOGY, AKURE'S UNDERGRADUATES' WHATSAPP CONVERSATIONS USING GRICE'S COOPERATIVE PRINCIPLE}

This section explained the analysis of the Federal University of Technology, Akure's undergraduates' WhatsApp conversations using Grice Cooperative Principle

Table 4.1: FUTA's Conversation One

\begin{tabular}{|l|l|c|c|c|c|}
\hline S/N & Conversation Strings & \multicolumn{3}{l|}{$\begin{array}{l}\text { Cooperative Principle compliance and } \\
\text { violation/flouting }\end{array}$} \\
\hline & & Quality & Quantity & Manner & Relation \\
\hline & Conversation One & & & & \\
\hline A & Hello & $\checkmark$ & $\checkmark$ & $\checkmark$ & $\checkmark$ \\
\hline B. & $\begin{array}{l}\text { BREAKING NEWS } \\
\text { You cannot repay your } \\
\text { family, friends and loved } \\
\text { ones for all they worth but } \\
\text { you can at least appreciate } \\
\text { them on their occasions }\end{array}$ & $\checkmark$ & $\checkmark$ & $\checkmark$ \\
\hline B & $\begin{array}{l}\text { WANT TO SURPRISE YOUR } \\
\text { LOVED ONES? }\end{array}$ & $\checkmark$ & & $\checkmark$ & $\checkmark$ \\
\hline B & This is what we specializein & & & & \\
\hline
\end{tabular}




\section{Maxim of Quality}

In string one of this conversation, all the maxims were obeyed. String four flouted this maxim because the clause was incomplete and thereby put members of the group in suspense. The clause was "This is what we specialize in ....

\section{The maxim of quantity}

String two had the maxim of quantity flouted; "Breaking News". This does not give full information; rather it kept readers in suspense, thereby flouting the quantity maxim.

String three also flouted the maxim of quantity. The string reads "you cannot repay your family, friends and loved ones for all they worth but you can at least appreciate them on their occasions". The information can be said to be incomplete because what we can use to appreciate them was not mentioned.

String four; "want to surprise your loved ones" flouted all the maxims.

It was a question really, but it was not clear if the speaker has adequate evidence of the question. For the maxim of quantity, the subject of the clause was missing.

Structurally, the clause should be written as "Do you want to surprise your loved ones?"

\section{The maxim of manner}

String four was obscure. It was full of suspense. Nobody knows what the surprise was going to be.

\section{The maxim of relation}

String four did not relate to the former strings, so no relevance.

Table 4.2: FUTA's Conversation Two

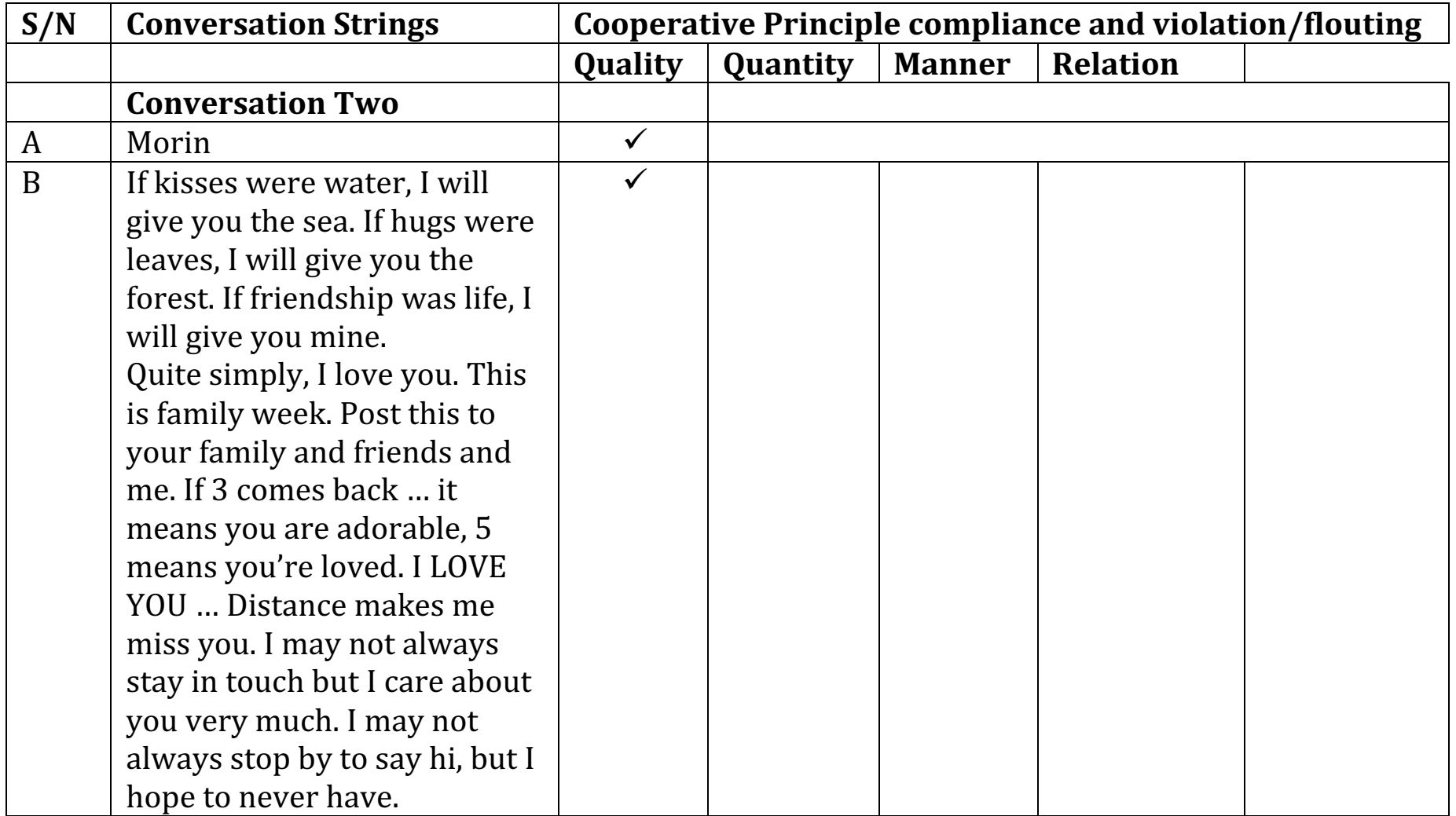


The conversation had two strings. All the maxims were obeyed.

There is an addresser who first sent greeting and the addressee replied the second day expressing his or her emotions with various emojis and smileys revealing the extent of love he had for the addresser.

The use of emojis and smileys served as the e-context. This string satisfied the maxim of quality and quantity.

Then, the maxim of relation and maxim of manner were also obeyed.

There was no obscurity and the message was relevant.

Table 4.3: FUTA's Conversation Three

\begin{tabular}{|l|l|l|l|c|c|}
\hline S/N & Conversation Strings & \multicolumn{3}{l|}{$\begin{array}{l}\text { Cooperative Principle compliance and } \\
\text { violation/flouting }\end{array}$} \\
\hline & & Quality & Quantity & Manner & Relation \\
\hline & Conversation Three & & & & \\
\hline A & Bros & $\checkmark$ & $\checkmark$ & $\checkmark$ & $\checkmark$ \\
\hline A. & Happy birthday o o & $\checkmark$ & $\checkmark$ & $\checkmark$ & $\checkmark$ \\
\hline B. & Tanks & $\checkmark$ & $\checkmark$ & $\checkmark$ & $\checkmark$ \\
\hline A. & Anything for us & $\checkmark$ & $\checkmark$ & $\checkmark$ & $\checkmark$ \\
\hline
\end{tabular}

\section{The maxim of quality}

String one flouted the maxim of quality. The string was "Bros". The information was vague.

String three flouted the maxim of quality; the spellings do not portray giving of thanks. It means another thing.

\section{Maxim of quantity}

String one also flouted the maxim of quantity. The string was "Bros". The information was insufficient.

String three flouted the maxim of quantity. It had insufficient information.

String two obeyed all the maxims. The information there was sufficient, truthful and relevant and without obscurity.

String four; there was no flouting of any of the maxims. 
Table 4.4: FUTA's Conversation Four

\begin{tabular}{|l|l|l|c|c|c|}
\hline S/N & Conversation Strings & \multicolumn{2}{l|}{$\begin{array}{l}\text { Cooperative Principle compliance and } \\
\text { violation/flouting }\end{array}$} \\
\hline & Quality & Quantity & Manner & Relation \\
\hline A. & Conversation Four & & & & \\
& $\begin{array}{l}\text { How to deal with someone who } \\
\text { disturbs you with calls ... Go to } \\
\text { OLX, advertise iPhone 7 for } \\
\text { N40,000, leave his number as a } \\
\text { contact, then sit back, smile } \\
\text { and drink chilled coke. Then } \\
\text { watch God fighting your battle } \\
\text {.. }\end{array}$ & $\checkmark$ & $\checkmark$ & $\checkmark$ & $\checkmark$ \\
\hline B & Emojis drawn & & & \\
\hline C & Lol... & $\checkmark$ & & & \\
\hline
\end{tabular}

The conversation was a group chat.

The string one of the conversation carried the whole message.

The string one obeyed all the maxims. Emojis and smileys were also put on the WhatsApp page for more explanation of the message.

It was a very funny message that the addresser sent to the addressee. The addresser gave a remedy to stop someone that disturbs with calls.

String two was purely emojis: a smiley laughing with an open mouth and a kudos sign.

\section{The maxim of quantity}

String three was from another contributor in the group, he/she said 'lol...' meaning 'laughing out loud'. The third string flouted the maxim of quantity, "lol..." was an abbreviation of laughing out loud. With the ellipses in front of the 'lol', it means there were other things to be said by the speaker, but was not said.

Table 4.5: FUTA's Conversation Five

\begin{tabular}{|l|l|c|c|c|c|}
\hline S/N & Conversation Strings & \multicolumn{2}{|l|}{$\begin{array}{l}\text { Cooperative Principle compliance and } \\
\text { violation/flouting }\end{array}$} \\
\hline & \multicolumn{1}{|l|}{ Quality } & Quantity & Manner & Relation \\
\hline A. & Conversation Five & & & & \\
\hline & $\begin{array}{l}\text { Chaii Xmas and new year } \\
\text { gone... Just like that??? } \\
\text { Back to school stress/ } \\
\text { work wahala .....No No } \\
\text { No... When is john the } \\
\text { baptist's birthday? That } \\
\text { guy needs to be celebrated } \\
\text { too. This holiday must } \\
\text { continue!!! }\end{array}$ & $\checkmark$ & $\checkmark$ & $\checkmark$ & \\
\hline
\end{tabular}

This conversation was also a string. 
It was also a group chat; the writer obeyed all the maxims.

Emojis and smileys were used to support the e-context.

The information was clear, coherent, relevant and plain

Table 4.6: FUTA's Conversation Six

\begin{tabular}{|l|l|l|l|c|c|}
\hline S/N & Conversation Strings & \multicolumn{3}{l|}{$\begin{array}{l}\text { Cooperative Principle compliance and } \\
\text { violation/flouting }\end{array}$} \\
\hline & & Quality & Quantity & Manner & Relation \\
\hline & Conversation Six & & & & \\
\hline 1 & Cul cul & & & & \\
\hline 2. & Da nice & & & & \\
\hline 3. & Yes & $\checkmark$ & & & \\
\hline 4. & So wetin dey dis mrng na. & $\checkmark$ & $\checkmark$ & $\checkmark$ & $\checkmark$ \\
\hline
\end{tabular}

It had four strings.

In the first three strings, all the maxims were flouted, except in string three where the maxim of quality was obeyed.

The last string obeyed all the maxims. It reads "so wetin de dis mrng na".

Structurally, the grammar was poor.

Pidgin was used to convey the message.

Findings in the analysis of FUTA's undergraduates' WhatsApp conversations using Grice's Cooperative Principle

This reports the findings on the analysis of FUTA's undergraduates' WhatsApp conversations using Grice's Cooperative Principle.

Table 4.7: Frequency table of FUTA's undergraduates' WhatsApp conversations using Grice's Cooperative Principle analysis

\begin{tabular}{|l|l|l|}
\hline & FUTA \\
\hline Maxims & Obeyed & Flouted \\
\hline Maxim of quality & $68.40 \%$ & $31.60 \%$ \\
\hline Maxim of quantity & $47.30 \%$ & $52.70 \%$ \\
\hline Maxim of manner & $7.40 \%$ & $92.60 \%$ \\
\hline Maxim of relation & $7.40 \%$ & $92.60 \%$ \\
\hline
\end{tabular}




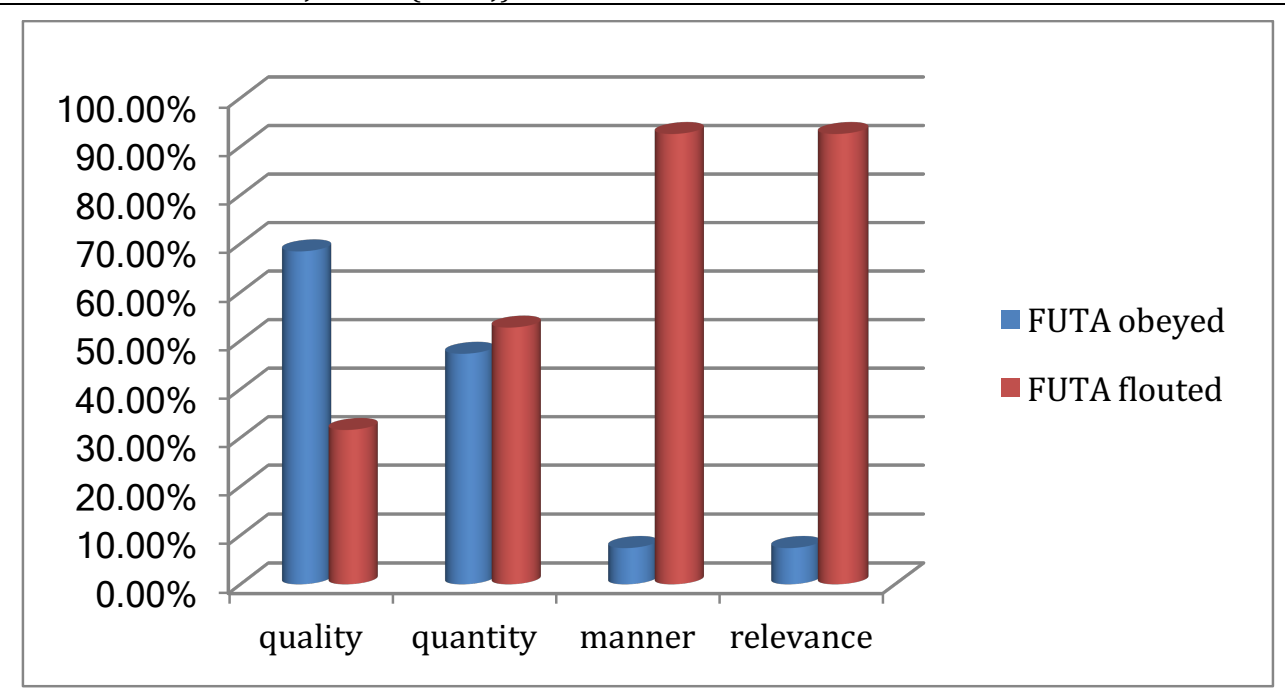

Figure 4.7: Analysis of Grice's Cooperative Principle of the Federal University of Technology, Akure's undergraduates' WhatsApp conversations

Figure 4.7 shows the representation of the results' percentages. The calculation formula is the same with the other university's formula for both flouting and obeisance.

The maxim of quality had $68.4 \%$, the maxim of quantity had $47.3 \%$, and the maxim of manner had $7.4 \%$ while the maxim of relation had $7.4 \%$ also. The maxim of quality had the highest of all the maxims, while the maxim of quantity had $47.3 \%$ which is relatively high too. This revealed that the level of cooperation is high to some extent between the conversationalists in FUTA's data. The maxims of relation and manner were of the same percentages (7.4) and these revealed that the rate of obscurity and the rate if diversion from the topic of discussion was high.

\section{CONCLUSIONS ON GRICE'S COOPERATIVE PRINCIPLE ANALYSIS OF FUTA'S UNDERGRADUATES.}

\section{Maxim of quality}

One of the attributes of undergraduates, especially the female ones is "talking". The results of maxim of quality from FUTA implied that most undergraduates were factual and truthful in their chats in the selected WhatsApp conversations.

\section{Maxim of quantity}

In FUTA's data, the rate at which the maxim of quantity was flouted was higher than the rate of obedience to the maxim. This implied that the information in the data was insufficient and was not as informative as required. Green (1996, p.70) argues that rationality and cooperativeness were the characteristics common to all speakers in the world, but that, non-cooperative conversations should be regarded as cooperative considering more global themes including listener and speaker. Also, Cappella (1995, p. 70) is of the opinion that rejecting the cooperative principle as a norm may lead to inefficient and unfinished interactions. This study supports Cappella 1995's view that for the fact that the rate of flouting of the maxim of quantity by FUTA's undergraduates led to inefficient and unfinished interactions among the conversationalists. (Cappella 1995, P.1)

\section{Maxim of Relation}

FUTA's results implied that most of the conversations on their selected WhatsApp pages were irrelevant. This might be due to the fact that, sometimes, human interactions may be illogical 
and irrational and that resistance and non-cooperation was the preferred discursive strategy at that point in time. This view is supported by Ladegaard $(2008$, p. 71$)$

\section{Maxim of Manner}

FUTA's results on the maxim of Manner implied that most of the conversations on their WhatsApp pages revealed that information was hidden, not plain, and were obscured.

From a Sociolinguistics perspective, Sex/Gender was seen as a factor that revealed the various ways people use English language in the WhatsApp of the undergraduates in the selected universities. Though gender constituents were not documented in the study, but through the tone of the interlocutors, the researcher was able to deduce the female voices in the interlocutions. Since during the collection of the data, there was no chance of asking the participants whether a particular message was from a female or male. Contrary to the position of Labov (1990), that women were more conservative linguistically than men, in the data collected for this study, it was revealed that women used a higher frequency of new forms than men.

Social class was another sociolinguistic factor that allowed the English language to function in various ways in the collected data. The fact that the subjects or participants were undergraduates revealed the level of education and the class of elites to which the conversationalists/interlocutors belong.

It was also discovered that once a change is initiated by a single individual (for whatever reason) its subsequent spread throughout a language community occur and to the extent that it is imitated by other speakers. For instance that was why there was widespread of slang, coinages, short forms and abbreviations usage in the WhatsApp conversations collected as the data for this study. This is due to the fact that WhatsApp is a viral application. This can be referred to as the role of imitation in Sociolinguistics.

\section{RECOMMENDATION}

This study therefore recommends that students should be more truthful and concise in making their thoughts known in other to reduce flouting of Maxims of cooperation in conversations.

\section{References}

Abdi, R., Rizi, M. T. \& Tarakoli, M. (2009). The Cooperative Principle in Discourse Communities and genres. A Framework of the use of Meta-Discourse. Journal of Pragmatics 42(6), 1669-1679, June 2010. Retrieved $29 / 3 / 2017$

Attardo, S. (1990).The violation of Grice's maxims in jokes Proceedings of the Sixteenth Annual Meeting of the Berkeley Linguistics Society (1990), 355-362

Banjo, A. (2014).The Deteriorating use of English in Nigeria, In Adenike Akinjobi (ed.) English Language Clinic Lecture Series 1-5, 1. Ibadan: University of Ibadan, Edunjobi Enterprises Ibadan. pp. 8-9

Capella, J. N. (1995). An evolutionary psychology of Gricean cooperation Journal of Language and Social Psychology, SAGE journals.

Conner, O. (2015). How to use WhatsApp to Conduct Research https://www.linkedin.com>pulse $>$ how-...

Cross, C. (2017, March 6). African Governments versus Social Media: Why the Uneasy Relationaship? THE CONVERSATION Academic.rigour.journalistic flair.Retrieved 4/5/17

Green, V.A. (2006). Children's cooperative and competitive interactions in limited resource situation: A literature review Applied Developmental Psychology ELSEVIER (available online in 2006) 42-59

Grice, P. (1975). Logic and Conversation. In Cole and Morgan (eds.) Syntax and Semantics 3, New York: Academic Press pp. 183-198 
Hadi, L. (2013). A Critical Appraisal of Grice's Cooperative Principle. Open Journal of Modern Linguistics 3(1), 6972. http.//www.scrip.org/journal/ojml Retrieved 29/3/17

Halliday, M. A. K. (1970). Language Structure and Language Function, In Lyons, J. (ed.) New Horizons in Linguistics. England: Penguin Books

Higgs, M. (2014, January 15). Texting is bound to decline but it won't die out just yet. THE CONVERSATION Academic.rigour.journalistic flair. Retrieved 4/5/17

Juez, L. A. (1995). Verbal irony and the maxims of Grice's Cooperative Principle.Revista Alicantina de Estudios 8. (1995): 25-30 Retrieved 29/3/17

Kazemi, F. \& Ebrahimi, A. (2016).The study of Grice principle application in commercialadvertisements of Hamshahri and Jame Jam newspapers.International Journal onStudies in English Language and Literature.(IJSELL) 4(9), September 3134 (online) Retrieved 29/3/17

Kheirabadi, R. and Aghagolzadch, F. (2012).Grice's cooperative maxims as linguistic criteria for News selectivity.Theory and Practice in Language Studies, 2(3), 5474-553, March 2012 (C) 2012. Academy Publisher Manufactured in Finland. ISSN 1799-2591. Retrieved 29/3/17

Labov, W. (1990). The intersection of sex and social class in the course of linguistic changeLanguage variation and change, 2,205-54 In Florian Coulmas (ed.) The HandbookofSociolinguistics. USA: Blackwell Publishing Limited. P. 81-82

Ladegaard, H. J. (2008). Pragmatic cooperation revisited: Resistance and non-cooperation as discursive strategy in asymmetrical discourses. Journal of Pragmatics, in Press.

Li, Q. (2015). The application of cooperative principle in Oral English learning,International Journal on Studies in English Language and LiteratureIJSELL 3(1),39 - 48. ISSN 2347-3126 (Print) \& ISSN 2347-3134 (Online) Retrieved $29 / 3 / 17$

Lindblom, K. (2001). Cooperating with Grice: a cross-disciplinary metaperspective on uses of Grice's Cooperative Principle. Journal of Pragmatics, ELSEVIER 33(10) 1601-1623

Napis, A. (2008). A study of Hedging and flouting of conversation maxims in the movie JohnTucker must Die. Thesis, English Letters and Language Department, Faculty of Humanitiesand Culture, the State Islamic University of Molang

Olsen, J. M. H. (2015). Sarcasm detection using Grice's maxims Undergraduate Journal of Humanistic Studies 1. Retrieved 29/3/17

Osisanwo, W. (2003). Discourse Analysis and Pragmatics. Lagos: Femolus Fetop Publishers. P.5

Pham, D. T. (2010). The Cooperative Principle: Does Grice's framework fit Vietnamese language Culture? Journal of Linguistics and Language Teaching. 1(2), pp. 197-219.

Shuwei, Y. (2004). The use of Grice's cooperative principle in Chinese TV talk shows. M. A Thesis, University of Malaya

Taghiyev, I. (2017). Violation of Grice's maxims and ambiguity in English Linguistics JokesProceedings of INTCESS $20174^{\text {th }}$ Interactional Conference on Education and Social Sciences 6-8 ISBN: 978-605-64453-9-2, February 2017 - Instanbul, Turkey

Xiaosu, Y. (2009). Conversational implicatures analysis of humour in American situation comedyFriends. A Dessertation submitted to University Gent. Retrieved 29/3/17

Yeboah, J., Ewur G. D. (2014). The impact of WhatsApp messenger usage on students'performance intertiary institutions in Ghana. Journal of Education and Practice, 5(6) ISSN 2222-1735(PAPER) ISSN 2222-288X (Online)

Zhou, M. (2009). Cooperative principle in Oral English teaching.International Education Studies, 2(3). Retrieved $29 / 3 / 17$

Zor, B. M. (2006). Using Grice's cooperative principle and its maxims to analyse problems coherence in Turkish and English Essays.M.A. Dessertation, Middle East Technical University. Retrieved 29/3/17 


\section{APPENDIX}

\section{NOVEMBER 5, 2016}

\section{Morin 8:56 AM}

\section{NOVEMBER 6, 2016}

If kisses were water 0 , I will give you the sea 0 . If hugs leaves of I will give the forest If friendship mine Quite simply, I love you $\bigcirc$. This is Family Week. Post this message to your family and friends and me $($ If 3 come back.. you're adorable, 5 means you're loved. I LOVE YOU $\Theta$... Distance makes me miss you. I may not always stay in touch but I care very much. I may not always stop by

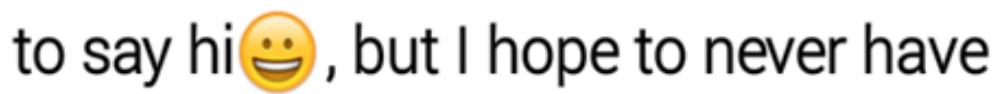
to say goodbye $*$. I may not prove to 
Shepe for u, produce by bokoaram, service by nigerdelta

\section{Ok $\quad$ 8:39 AM}

\section{No kwam 8:39 AM}

When r u comn to lb $\quad 8: 39$ AM

$$
\text { But one of dis wkend shaa 9:01 AM }
$$




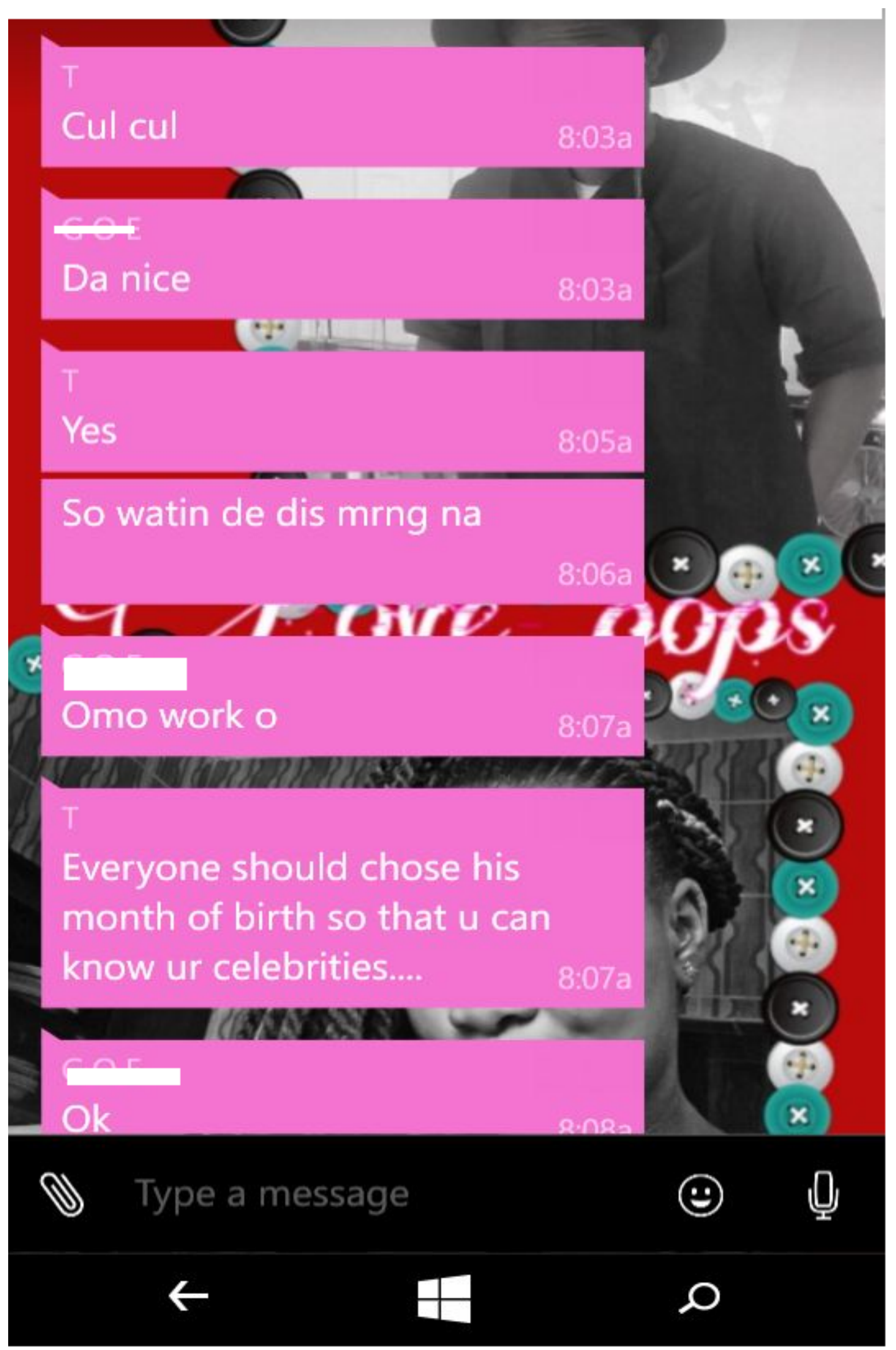


secured with end-to-end encryption. Tap for more info.

\section{Hello 10:40 AM $\checkmark$}

\section{谈 BREAKING NEWS}

$\checkmark$ You can not repay your family, friends and loved ones for all they worth but you can at least appreciate them on their occasions.

WANT TO SURPRISE YOUR LOVED ONES?

- $)$ This is what we specialise in...

WE MAKE PORTRAITS (PAINTING AND PENCIL) AND COMPLEMENTARY CARDS TO SUIT ANY OCCASION @ *very affordable price contact 